\title{
ANTI-ACNE GEL OF ISOTRETINOIN: FORMULATION AND EVALUATION
}

\author{
SHREYA NIKAM* \\ Department of Pharmaceutics, Arvind Gavali College of Pharmacy, Jaitapur, Satara, Maharashtra, India. Email: spnikam82@gmail.com
} Received: 04 May 2017, Revised and Accepted: 27 July 2017

\begin{abstract}
Objective: Isotretinoin is a very effective drug in the treatment of acne vulgaris by topically. The objective of present study was formulation development of anti-acne gel using Isotretinoine and span 80 for topical delivery to cure nodulosystic acne vulgaris. Furthermore, the comparative study of all the evaluation parameters done with marketed formulation of same drug.
\end{abstract}

Methods: Formulation of anti-acne gel of isotretinoin using Carbopol 940 as a polymer and incorporating isotretinoin in form of topical semi-solid gel using magnetic stirrer, Cremophor RH 40, and butylated hydroxytoluene. Drug was uniformly dispersed in Cremophor RH 40 and the respected solvents. Ethanol, isopropyl alcohol, and glycerin were used as solvents in 15\% quantity. Further, the formulation was evaluated for physicochemical evaluation of gel formulations. The prepared gel were optimized statistically and characterized for pH, spredability, drug content, viscosity, in vitro diffusion study, acute skin irritation test, and antimicrobial activity. Evaluation test was also compared with marketed formulation of isotretinoin, that is, Sortet gel. The antibacterial and anti-acne activity of different formulations was determined by modified agar well diffusion method on the culture of Propionibacterium acne also compared with marketed formulation.

Results: The optimized batch (B10) showed highest spreadability (32.422 $\mathrm{g} / \mathrm{cm}^{3}$ ) in all formulations and also have high percentage of drug contents $(95.60 \%)$. The spreadability value was $17.998 \mathrm{~g} / \mathrm{cm}^{3}$ showing good spreadability. The viscosity of optimized batch was observed less as compared to other formulations, ultimately showed releases also more. In the in vitro diffusion study, B10 batch release $85.69 \%$ of the drug as compared to Sotret gel. The antibacterial activity was studied on anaerobic microorganism $P$. acne, compared with marketed Sortet gel. Optimized batch showed maximum zone of inhibition to P. acne below marketed formulations and standard benzyl peroxide gel.

Conclusion: The topical anti-acne gel of isotertinoin was successfully formulated and evaluated for different parameters. The results indicate that the active component, that is, isotertinoin is more effective when subjected in gel formulations and produces effective anti-acne activity in the management of nodulosystic acne vulgaris.

Keywords: Formulation, Isotretinoin, Topical gel, Anti-acne activity, Propionibacterium acne.

(C) 2017 The Authors. Published by Innovare Academic Sciences Pvt Ltd. This is an open access article under the CC BY license (http://creativecommons. org/licenses/by/4. 0/) DOI: http://dx.doi.org/10.22159/ajpcr.2017.v10i11.19614

\section{INTRODUCTION}

Semi-solids constitute a significant proportion of pharmaceutical dosage forms. They serve as carriers for drugs that are topically delivered by way of the skin, cornea, rectal tissue, nasal mucosa, vagina, buccal tissue, urethral membrane, and external ear lining. Because of their peculiar rheological behavior, semi-solids can adhere to the application surface for sufficiently long periods before they are washed off. This property helps prolong drug delivery at the application site. Acne vulgaris is a common skin disease, affecting about $70-80 \%$ of adolescents and young adults. It is a multifactorial disease of the pilosebaceous unit [1]. The influence of androgens at the onset of adolescence leads to an enlargement of the sebaceous gland and a rise in sebum production. Additional increased proliferation and altered differentiation of the follicular epithelium eventually blocks the pilosebaceous duct, leading to the development of the microcomedo as the primary acne lesion. Concomitantly and subsequently, colonization with Propionibacterium acnes increases followed by induction of inflammatory reactions from bacteria, ductal corneocytes, and sebaceous pro-inflammatory agents. Topical retinoid has been used in acne therapy since 1962. The first one was tretinoin, which remains in use today. Due to tretinoin's irritative potential, new formulations with much better tolerability have been developed. Other retinoid-like agents with a different retinoid receptor-binding profile, most importantly adapalene, show much less irritancy and thus better compliance with a comparable clinical effect on comedonic and inflammatory acne lesion. Thus, facts have clearly indicated that a formulation and development of a gel-based topical dosage form for the anti-acne drug will be proved to be worthwhile. Hence, a study on formulation and evaluation of gels for a new antiacne drug-"isotretinoin" was selected as the principle object of this project work. Topical application of gels overcomes the problems to be associates with other dosage forms are, avoidance of the first-pass metabolism, convenient and easy to apply, avoidance of the risks and inconveniences of intravenous therapy and of the varied conditions of absorption, such as $\mathrm{pH}$ changes, presence of enzymes, gastric emptying time, achievement of efficacy with lower total daily dosage of drug by continuous drug input, avoids fluctuation in drug levels, inter- and intra-patient variations, and ability to easily terminate the medications, when needed.

A relatively large area of application in comparison with buccal or nasal cavity, ability to deliver drug more selectively to a specific site, and avoidance of gastro-intestinal incompatibility.

Providing utilization of drugs with short biological half-life, narrow therapeutic window. Improving physiological and pharmacological response and patient compliance provides suitability for self-medication [2].

Therefore, the aims of this study were (a) to develop isotretinoin anti-acne gel using Carbopol 940 polymer with different concentrations of solvents such as ethanol, isopropyl alcohol, and glycerin, and drug-solubilizer Cremophor RH 40 and (b) to study the evaluation criteria for it. 


\section{MATERIALS AND METHODS}

\section{Materials}

The drug isotretinoin USP was as gift sample from Cosme Pharma Laboratories Limited, Mumbai. Cremophor RH 40 purchased from Zeel pharmaceuticals, Mumbai. Sotret gel purchased from Ranbaxy Pharmaceuticals. Propionibacterim acne culture MTCC 1951 was purchased from the M.T.C.C., Institute of Microbial Technology, Chandigarh (India).

\section{Equipment}

Ultraviolet (UV)/visible-spectrophotometer (Systronic AU2701, double beam), Fourier transform-infrared spectrophotometer (FT-IR) (Perkin-Elmer, Shivaji University Kolhapur), Homogenizer (Remi Motors, RQ127 A), magnetic stirrer (Remi Motors), Digital pH Meter (HI96107), Franz diffusion cell, spreadability apparatus, small volume Brookfield viscometer, Sonicator (Single Phase, 230 VAC, D-120/IH), distillation apparatus (Bio Technics, India), and analytical balance.

\section{Analytical method development}

Determination of $\lambda_{\max }$ of Isotretinoin spectrum scan by $U V$ spectroscopy

Procedure

Stock solution of isotretinoin was prepared in phosphate buffer $\mathrm{pH}$ 5.8: Ethanol $(65: 35 \mathrm{v} / \mathrm{v})$ solution. The concentration of stock solution was $40 \mu \mathrm{g} / \mathrm{mL}$.

The scanning of the isotretinoin was performed in UV spectrophotometer. The solvent used for the spectrum analysis was mixture of phosphate buffer pH 5.8: Ethanol (65:35) and the scanning was done. The maximum absorption of isotretinoin was found at $340 \mathrm{~nm}$. Standard calibration curve for isotretinoin in ethanol: Phosphate buffer pH 5.8.

\section{Preparation of phosphate buffer pH 5.8}

A volume of $50 \mathrm{~mL}$ of $0.2 \mathrm{M}$ potassium dihydrogen phosphate were placed in $200 \mathrm{~mL}$ of volumetric flask and add $3.6 \mathrm{~mL}$ of $0.2 \mathrm{M} \mathrm{NaOH}$. Then, distilled water was added to make volume.

A volume of $100 \mathrm{~mL}$ of $0.2 \mathrm{M} \mathrm{KH}_{2} \mathrm{PO}_{4}$ and $7.2 \mathrm{~mL} \mathrm{NaOH} 0.2 \mathrm{M}$ were mixed and volume was made $400 \mathrm{~mL}$ with distilled water and $\mathrm{pH}$ was checked at 5.8 by digital pH Meter $325 \mathrm{~mL}$ of above solution and $175 \mathrm{~mL}$ of ethanol then mixed. This was our phosphate buffer: Ethanol mixture for dilution [3].

\section{Procedure}

1. $200 \mathrm{mg}$ drug isotretinoin was weighed and mixed with $100 \mathrm{~mL}$ solvent, that is, phosphate buffer pH 5.8: Ethanol $(65: 35 \mathrm{v} / \mathrm{v})$, concentration was $2000 \mu \mathrm{g} / \mathrm{mL}$.

2. $10 \mathrm{~mL}$ of above solution was again diluted with $100 \mathrm{~mL}$ with solvent; the concentration was $200 \mu \mathrm{g} / \mathrm{mL}$.

3. Then, $20 \mathrm{~mL}$ of solution of step 2 , was diluted to $100 \mathrm{~mL}$ with solvent, the final concentration of solution was $40 \mu \mathrm{g} / \mathrm{mL}$.

Stock solution was further diluted and the absorbance of diluted solution was taken using UV spectrophotometer

The procedure was repeated 5 times and mean was taken for the standard calibration curve. Absorbance was measured at $340 \mathrm{~nm}$ against ethanol: Phosphate buffer as blank solution.

\section{Pre-formulation test for isotretinoin}

Pre-formulation studies of API were carried out to study incompatibility between the excipients used.

\section{Drug-polymer interaction study}

In pre-formulation study, drug and polymer interaction was studied by FT-IR study. Before formulation of any dosage form, it is very important to check the compatibility of all excipient with the drug, whether the polymer or excipient used in the formulation cannot affect the drug nature or chemical structure. Hence, it was studied by doing the FT-IR study of drug along with polymer and excipient. FT-IR spectra of drug molecule, isotretinoin-ethanol, isotretinoin-isopropyl alcohol, isotretinoin glycerin, isotretinoin-Carbopol 940, isotretinoinCremophor RH40, isotretinoin, butyalated hydroxytoluene, isotretinointriethanolamine, and isotretinoin-all excipients were obtained on FT-IR spectrophotometer (PERKIN ELMER). The spectra were scanned over wavelength region of 4000-400 $\mathrm{nm}$.

\section{Preparation and composition of gel}

The anti-acne gel of isotretinoin was prepared by first, required quantity of Carbopol 940 was taken. It was taken as $0.5 \mathrm{~g}, 0.75 \mathrm{~g}$, and $1 \mathrm{~g}$ in all 11 batches.

Required quantity of Carbopol 940 was accurately weighed on analytical balance and sprinkled on specific quantity of water and kept for hydration for $24 \mathrm{hrs}$ and then stirred slowly using magnetic stirrer to form uniform mixture. At the same time, in another beaker drug, Cremophor RH 40 [3] butylated hydroxytoluene, was accurately weighed. Drug was uniformly dispersed in Cremophor RH 40 and the respected solvents. Ethanol, isopropyl alcohol, and glycerin were used as solvents in $15 \%$ quantity. Then, the uniform mixture of Carbopol 940 was neutralized slowly using trietahnolamine, without forming air bubble to form a clear, transparent gel, and then the mixture of drug with solvents and other ingredients was slowly mixed in above formed gel uniformly using the homogenizer. All the procedure was carried out by wrapping aluminum foil to glass wares to avoid degradation of drug isotretinoin [4].

\section{Evaluation of anti-acne gel of isotretinoin}

\section{Physicochemical evaluation of gel formulation}

Color, physical appearance, and homogeneity were tested by visual observation.

\section{pH}

The $\mathrm{pH}$ of the various formulations was determined using Digital $\mathrm{pH}$ Meter (HI 96107). A volume of $1 \mathrm{~g}$ of gel was dissolved in $100 \mathrm{ml}$ of distilled water and stored for $2 \mathrm{~h}$. The measurement of $\mathrm{pH}$ was done. The $\mathrm{pH}$ of gel formulations was in range $5.9 \pm 0.1-6.36 \pm 0.2$, which lies in the normal range of the skin and would not produce any skin irritation. There was no significant change in $\mathrm{pH}$ values as a function of time for all formulations in triplicate and average values were given in Table 1 [5].

\section{Spreadability}

Spreadability denotes the extent of area to which the gel readily spreads on application to the skin or affected part. Bioavailability of gel also depends on its spreading value.

The Spreadability was expressed in terms of time taken in seconds taken by two slides to slip off from the gel, placed in between the slide under certain load. Lesser is the time taken for separation of two slide, better is the spreadability.

A volume of $20 \mathrm{~g}$ weight was tied to the upper slide carefully. The time taken for the upper slide to travel the distance of $6.0 \mathrm{~cm}$ and separated away from the lower slide under the influence of the weight was noted. The experiment was repeated by 3 times and the mean time taken for calculation [5].

Spreadability was calculated using the following: Formula:

$\mathrm{S}=\mathrm{M} \times \mathrm{LT}$

Where,

S - Spreadability

M - Weight tied to the upper slide (20 g)

$\mathrm{L}$ - Length of the glass $(6 \mathrm{~cm})$

$\mathrm{T}$ - Time taken in seconds. 
Table 1: Formulation ingredients of isotertinoin gel (g)

\begin{tabular}{|c|c|c|c|c|c|c|c|c|c|c|c|}
\hline Ingredients & B1 E & B2 IA & B3 G & B4 E+I & B5 I+G & B6 E+G & B7 E+I+G & B8 E+G & B9 I+G & B10 E+I & B11 (blank E+I+G) \\
\hline Isotretinoin & 0.05 & 0.05 & 0.05 & 0.05 & 0.05 & 0.05 & 0.05 & 0.05 & 0.05 & 0.05 & - \\
\hline Ethanol & 14.99 & - & - & 10.00 & - & 5.02 & 5.02 & 10.00 & - & 5.03 & 5.03 \\
\hline Isopropyl alcohol & - & 15.01 & - & 5.03 & 15.01 & - & 5.03 & - & 5.03 & 10.00 & 10.00 \\
\hline Glycerin & - & - & 15.01 & - & - & 10.00 & 5.04 & 5.04 & 10.00 & - & - \\
\hline Cremophor RH 40 & 1 & 1 & 1 & 1 & 1 & 1 & 1 & 1 & 1 & 1 & 1 \\
\hline BHT & 0.04 & 0.04 & 0.04 & 0.04 & 0.04 & 0.04 & 0.04 & 0.04 & 0.04 & 0.04 & 0.04 \\
\hline Carbopol 940 & 0.5 & 0.75 & 01 & 0.5 & 0.75 & 01 & 0.5 & 0.75 & 01 & 0.5 & 0.5 \\
\hline Triethanolamine & 1.6 & 1.8 & 2.1 & 1.6 & 1.8 & 2.1 & 1.6 & 1.8 & 2.1 & 1.6 & 1.6 \\
\hline Distilled water & 6.6 & 6.6 & 6.6 & 6.6 & 6.6 & 6.6 & 6.6 & 6.6 & 6.6 & 6.6 & 6.6 \\
\hline Total weight & 100 & 100 & 100 & 100 & 100 & 100 & 100 & 100 & 100 & 100 & 100 \\
\hline
\end{tabular}

Table 2: Standard calibration curve for isotretinoin in ethanol:phosphate buffer pH 5.8

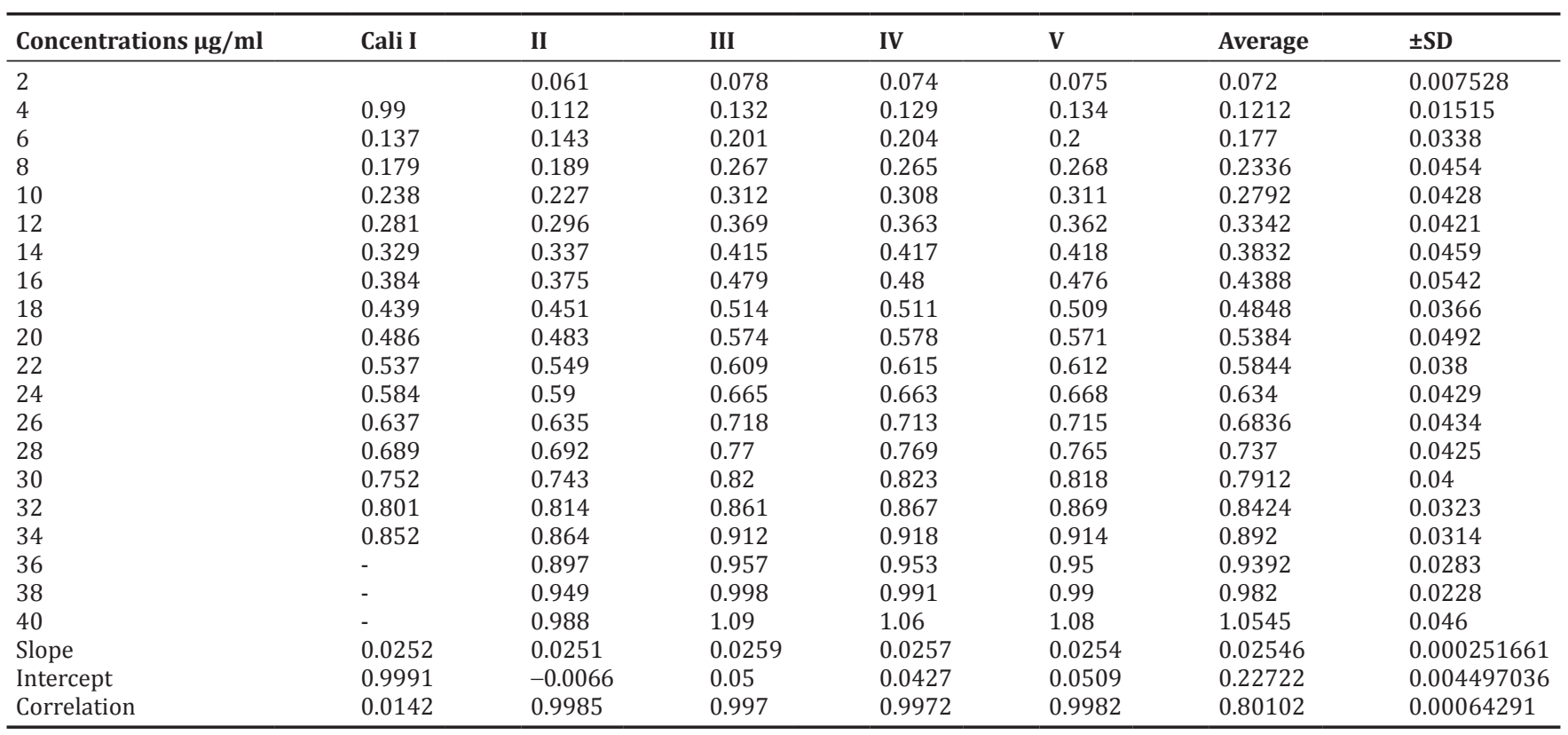

Table 3: Absorbance of standard calibration curve of isotretinoin

\begin{tabular}{ll}
\hline Concentrations $(\boldsymbol{\mu g} / \mathbf{m l})$ & Average \\
\hline 2 & 0.072 \\
4 & 0.1212 \\
6 & 0.177 \\
8 & 0.2336 \\
10 & 0.2792 \\
12 & 0.3342 \\
14 & 0.3832 \\
16 & 0.4388 \\
18 & 0.4848 \\
20 & 0.5384 \\
22 & 0.5844 \\
24 & 0.634 \\
26 & 0.6836 \\
28 & 0.737 \\
30 & 0.7912 \\
32 & 0.8424 \\
34 & 0.892 \\
36 & 0.9392 \\
38 & 0.982 \\
40 & 1.0545 \\
Slope & 0.0255 \\
Intercept & 0.0249 \\
Correlation & 0.9998 \\
\hline
\end{tabular}

Drug content

Procedure was carried out in subdued light. To a quantity of the gel containing $0.5 \mathrm{mg}$ of isotretinoin, $10 \mathrm{ml}$ of dichloromethane was added, shaken until all the gel has dispersed and dilute the solution to $100 \mathrm{ml}$ with $5 \mathrm{ml}$ of $0.1 \mathrm{M}$ hydrochloric acid to $250 \mathrm{ml}$ with ethanol (96\%). Measured the absorbance of the solution at maximum at about $356 \mathrm{~nm}$, using ethanolic hydrochloric acid solution in the reference cell. The content of $\mathrm{C}_{20} \mathrm{H}_{28} \mathrm{O}_{2}$ in gel was calculated taking 1350 as the value of a $(1 \%, 1 \mathrm{~cm})$ at maximum at about $356 \mathrm{~nm}$ using $\mathrm{UV}$-visible spectrophotometer (systronic double beam spectrophotometer). For the drug, content sample has taken from top, middle, and bottom from the container. The experiment was repeated for ten times for each batch, four times for top region, and three times for middle and bottom region, and then average value was taken for the drug-content calculation [6].

\section{Stickiness}

Stickiness was evaluated by just applying small quantity of gel and checking whether there was the presence or absence of stickiness after application of the formulation.

\section{Smell}

Evaluation of smell of gel formulation was done by checking the smell of formulation to 4-5 persons, and the observations of these were given as alcoholic, acceptable, or non-acceptable. 


\section{Viscosity}

The viscosity of gel formulation was determined using small volume Brookfield viscometer. The determinations were carried out four times at $6,12,30$, and $60 \mathrm{rpm}$ and that reading was multiplied by the factor and mean of that were taken as final viscosity in centipoises [4].

Brookfield factor finder was used as follows

Dial reading $\times$ factor $=$ Viscosity in centipoise $($ mpa.s $)$

\section{In vitro diffusion study}

In vitro diffusion study of the anti-acne gel formulation was done using the Franz diffusion cell. Franz diffusion cell has been the standard system used for the study of release of semi-solid drug formulations. $0.45 \mu$ dialyzing membrane was used. The media used for the in vitro diffusion was mixture of phosphate buffer pH 5.8: Ethanol $(65: 35) \mathrm{v} / \mathrm{v}$. The dialyzing membrane was soaked in phosphate buffer $24 \mathrm{hrs}$ before use. The temperature was maintained constant at $32^{\circ} \mathrm{C} .5 \mathrm{ml}$ sample was withdrawn and replaced with fresh solvent. The time interval was maintained as 15 minutes, 30 minutes, $1 \mathrm{hr}$, and 1.30 minutes up to $8 \mathrm{hrs}$. The drug concentration of receptor fluid was determined by UV spectrophotometer at $340 \mathrm{~nm}$. The correlation factor was included in the calculation to account for the drug loss during sampling. Thus, the amounts of drug permeation of all the formulations were calculated $[4,5,9]$.

\section{Acute skin irritation study}

The primary skin irritation test was performed on albino rats and weighing about 150-200 g. The animals were maintained on standard animal feed and had free access to water. The animals were kept under standard laboratory condition. The total mass was divided into four batches, each batch containing seven animals. Two batches of each were used for control and test. Dorsal hairs at the back of the rats were clipped off 1 day before the commencement of the study. Animals showing normal skin texture were housed individually in cages with copography meshes to avoid contact with the bedding. $50 \mathrm{mg}$ of the each formulation of different concentrations were applied over one square centimeter area of intact and abraded skin to different animals. Aqueous solution of $0.8 \%$ formalin was applied as a standard irritant. The animals were observed for 7 days for any signs of edema and erythema.

The gel was applied to the skin once a day for 7 days and observed for any sensitivity and the reaction if any was graded as:

A - no reaction, B - slight patchy erythema, C - slight but confluent or moderate but patchy erythema, D - moderate erythema, and E - severe erythema with or without edema. The skin irritation studies showed that anti-acne gel formulations dose not produces any severe irritation, redness of skin, along with the marketed Sotret gel of isotretinoin, whereas the $0.8 \%$ formalin was used as a standard irritant for the comparison (Ethical committee letter number: RCP/IAEC/201112/P-005) [5,9]

\section{Antibacterial study}

The antibacterial activity of different formulations was determined by modified agar well diffusion method. In this method, nutrient agar plates were seeded with $0.2 \mathrm{ml}$ of $24 \mathrm{hrs}$ broth culture of $P$. acnes. The plates were allowed to dry for $1 \mathrm{hr}$. A sterile $8 \mathrm{~mm}$ borer was used to cut four wells of equidistance in each of plates; $1 \mathrm{~g}$ of formulations (B1B10) and marketed Sotret gel for comparison. Benzoyl peroxide gel was used as a positive control, and distil water was used as negative control were introduced in to the wells at randomly. The plates were incubated at $37^{\circ} \mathrm{C}$ for $24 \mathrm{hrs}$. The antibacterial activities were found out by measuring the diameter of zones of inhibition (in $\mathrm{mm}$ ). This experiment repeated 3 times [8].

\section{RESULTS AND DISCUSSION}

\section{Determination of $\lambda_{\max }$ of isotretinoin spectrum scan}

The standard calibration was done by taking the average value and the concentrations, and the graph was ploted and the value of slope, correlation, and regration was calculated and these values are taken as standard for calculation in in vitro diffusion study.

\section{Pre-formulation test for isotretinoin}

\begin{tabular}{|c|c|c|}
\hline Tests & Specifications & Results \\
\hline Description & $\begin{array}{l}\text { Pale yellow to } \\
\text { yellow color, } \\
\text { microcrystalline } \\
\text { powder }\end{array}$ & $\begin{array}{l}\text { Pale-yellow, } \\
\text { microcrystalline } \\
\text { powder }\end{array}$ \\
\hline Solubility & $\begin{array}{l}\text { Practically } \\
\text { insoluble in } \\
\text { water, soluble } \\
\text { in chloroform, } \\
\text { sparingly soluble } \\
\text { in alcohol, } \\
\text { in isopropyl } \\
\text { alcohol, and in } \\
\text { polyethylene } \\
\text { glycol } 400\end{array}$ & $\begin{array}{l}\text { Practically, insoluble } \\
\text { in water, soluble in, } \\
\text { chloroform, sparingly } \\
\text { soluble in alcohol, } \\
\text { in isopropyl alcohol, } \\
\text { and in polyethylene } \\
\text { glycol } 400\end{array}$ \\
\hline Identification & $\begin{array}{l}\text { The infrared } \\
\text { spectrum of } \\
\text { the sample is } \\
\text { concordant with } \\
\text { the spectrum } \\
\text { obtained with } \\
\text { isotretinoin } \\
\text { reference } \\
\text { standard/working } \\
\text { standard } \\
\text { The absorptivities } \\
\text { at } 354 \text { nm do not } \\
\text { differ by more } \\
\text { than } 3.0 \%\end{array}$ & $\begin{array}{l}\text { The infrared } \\
\text { spectrum of the } \\
\text { sample is concordant } \\
\text { with the spectrum } \\
\text { obtained with } \\
\text { isotretinoin reference } \\
\text { standard/working } \\
\text { standard } \\
5 \text { kol-0.5397 } \\
5 \text { g- } 0.4728\end{array}$ \\
\hline $\begin{array}{l}\text { Loss on } \\
\text { drying }\end{array}$ & $\begin{array}{l}\text { Not more than } \\
0.5 \%\end{array}$ & $0.3 \%$ \\
\hline $\begin{array}{l}\text { Residue on } \\
\text { ignition }\end{array}$ & $\begin{array}{l}\text { Not more than } \\
0.1 \%\end{array}$ & $0.05 \%$ \\
\hline Heavy metals & $\begin{array}{l}\text { Not more than } \\
0.002 \%\end{array}$ & $<0.002 \%$ \\
\hline $\begin{array}{l}\text { Limit of } \\
\text { tretinoin }\end{array}$ & $\begin{array}{l}\text { Not more than } \\
0.1 \%\end{array}$ & $0.007 \%$ \\
\hline $\begin{array}{l}\text { Residual } \\
\text { solvents }\end{array}$ & $\begin{array}{l}\text { To comply with } \\
\text { USP }\end{array}$ & Complies \\
\hline Assay & $\begin{array}{l}\text { Contains not } \\
\text { less than } 98.0 \% \\
\text { and not more } \\
\text { than } 102.0 \% \\
\text { of isotretinoin } \\
\text { calculated on } \\
\text { dried basis }\end{array}$ & $99.1 \%$ \\
\hline $\begin{array}{l}\text { Extraneous } \\
\text { matter }\end{array}$ & Should be nill & Nil \\
\hline
\end{tabular}

Chemical analysis certificate

Name of product: Isotretinoin USP

Batch No: 20110103

Manufactured date: 2011/01/12

Expiry date: 2016/01/11.

\section{Drug polymer interaction study}

The major peaks were found in IR spectra of isotretinoin at wave number 3428.77 may be due to stretching vibration of $\mathrm{OH}$ group 
Table 4: Test for isotretinoin

\begin{tabular}{lll}
\hline Tests & Standards & Results \\
\hline Description & Yellow crystalline powder & Conforms \\
Identification & Conforms & Conforms \\
Organic volatile impurities & Conforms & Conforms \\
Heavy metals & $<20 \mathrm{ppm}$ & $<20 \mathrm{ppm}$ \\
Loss on drying & $\leq 0.5 \%$ & $0.3 \%$ \\
Residue on ignition & $\leq 0.1 \%$ & $0.04 \%$ \\
Limit of tretinoin & $\leq 0.1 \%$ & $0.10 \%$ \\
Assay & $98.0-102.0 \%$ & $99.6 \%$ \\
Conclusion & The result conforms with & \\
& above standards & \\
\hline
\end{tabular}

Table 5: IR interpretation of isotretinoin

\begin{tabular}{|c|c|c|}
\hline $\begin{array}{l}\text { Groups in } \\
\text { structure }\end{array}$ & $\begin{array}{l}\text { Ranges on } \\
\text { interpretation }\end{array}$ & Interpretation \\
\hline \multirow[t]{2}{*}{$\mathrm{OH}$} & $2500-3500$ & H-bonded \\
\hline & $3200-3400$ & Stretching, strong peak \\
\hline $\mathrm{C}=\mathrm{O}$ & $1680-1760$ & Carbonyl group, strong peak \\
\hline $\mathrm{C}=\mathrm{C}$ & $1600-1680$ & Aliphatic-alkene, weak peak \\
\hline $\mathrm{C}-\mathrm{C}$ & $800-1300$ & $\begin{array}{l}\text { Aliphatic-alkene-weak or medium, } \\
\text { stretching }\end{array}$ \\
\hline $\mathrm{C}=\mathrm{C}$ & $1450-1600$ & Aromatic-weak-(bending) \\
\hline \multirow[t]{5}{*}{$\mathrm{C}-\mathrm{C}$} & 1650 & Weak \\
\hline & 1580 & Weak \\
\hline & Near 1500 & Weak \\
\hline & 1450 & May be strong \\
\hline & $1200-1400$ & Aromatic \\
\hline C-H stretch & $2850-2960$ & Alkane, strong \\
\hline Aromatic $\mathrm{H}$ & $3000-3100$ & Medium \\
\hline
\end{tabular}

IR: Infrared

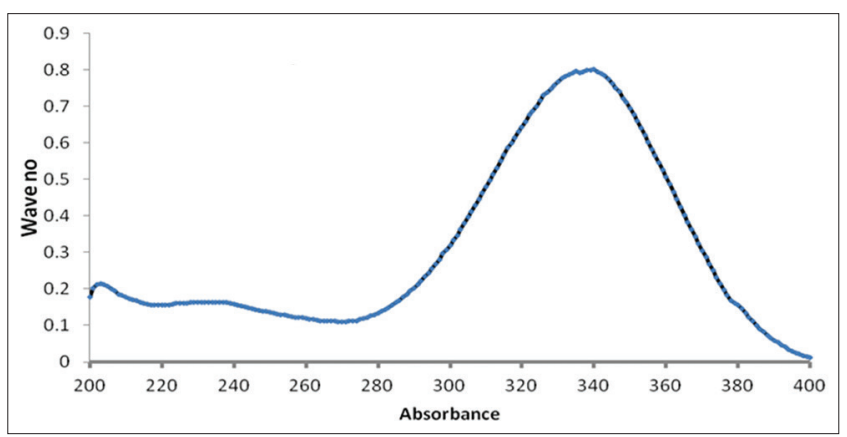

Fig. 1: Ultraviolet spectrum of isotretinoin

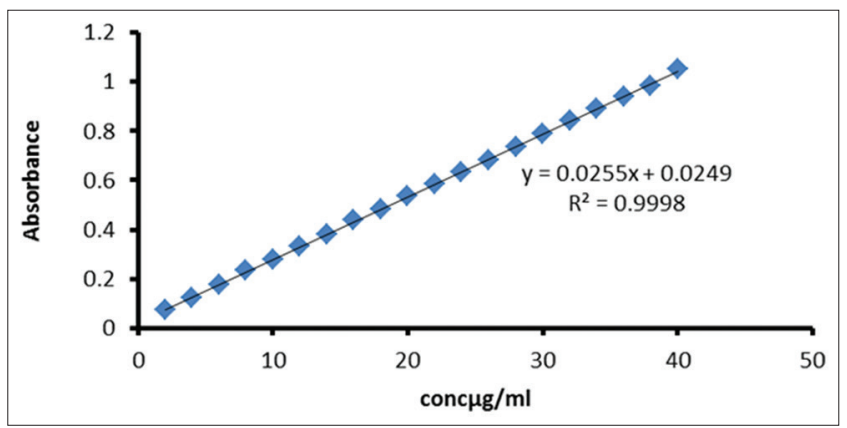

Fig. 2: Standard calibration curve of isotretinoin in buffer:ethanol (65:35 v/v) pH 5.8 by spectrophotometer at 340

and shows strong peak. Also at 3075 , it gives weak peak due to aromatic H. Then, also shows strong peak at 2927.53 due to $\mathrm{C}-\mathrm{H}$ stretch Alkene. Strong peak at 1673.04 for $\mathrm{C}=0$ group also gives strong peak at 1599.32 due to $\mathrm{C}=\mathrm{C}$ Aliphatic group, and also $\mathrm{C}=\mathrm{C}$

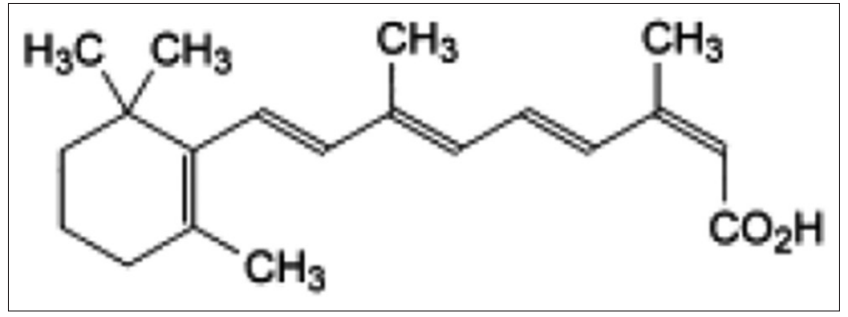

Fig. 3: Structure of isotretinoin

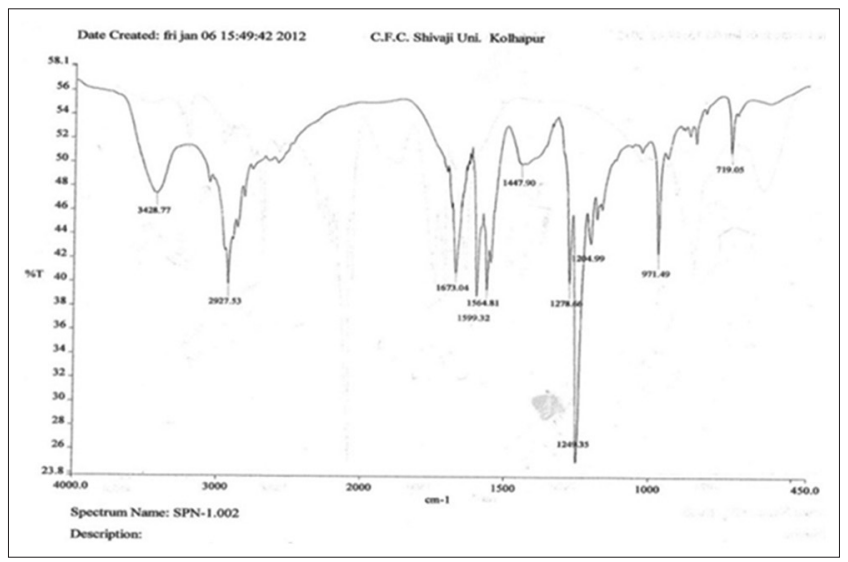

Fig. 4: Infrared of isotretinoin

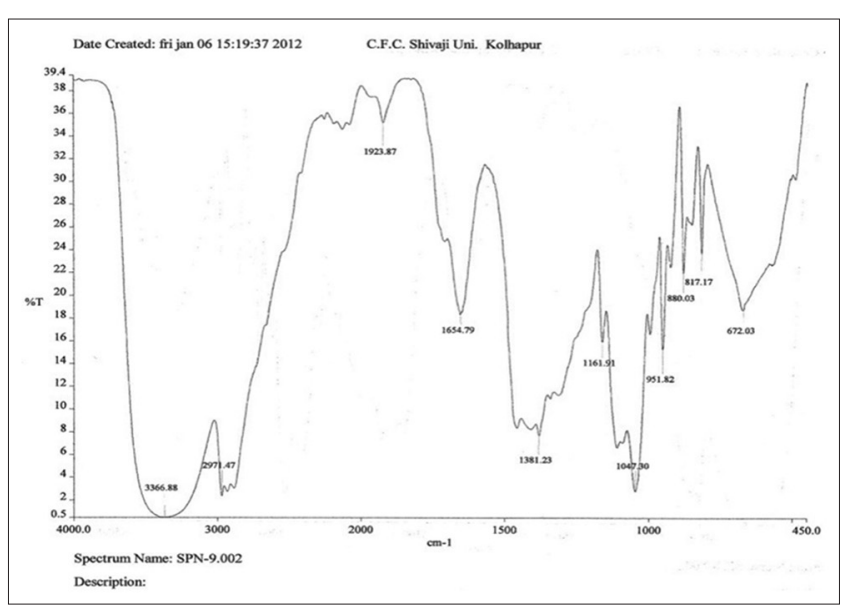

Fig. 5: Infrared spectrum of isotretinoin and mixture of all excipients

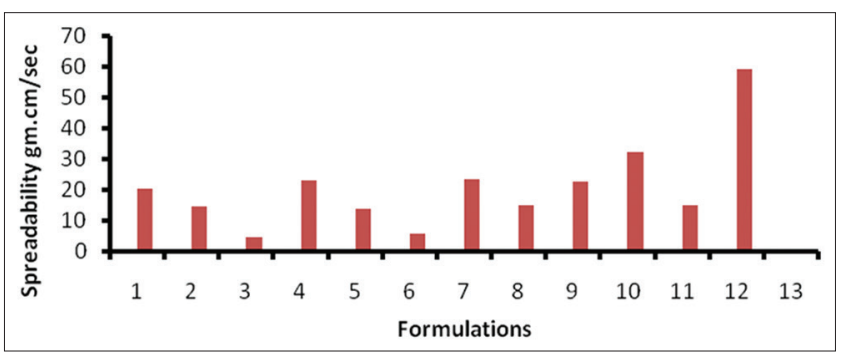

Fig. 6: Spreadability of anti-acne gel of isotretinoin formulations prepared using Carbopol 940 (average \pm SD)

Aromatic group gives strong peak at 1564.81. There were also deformations of $\mathrm{OH}$ group take place which gives broad shallow peak at 1447.90 range, and also gives strong peak at 1249.35 due to $\mathrm{C}$-C aromatic. 
IR spectroscopy of isotretinoin and all ingredients

From the IR spectroscopy of drug, polymer, and other solvents and excipients, it was observed that the drug and other excipients were compatible with each other and there was no chemical reaction among them.

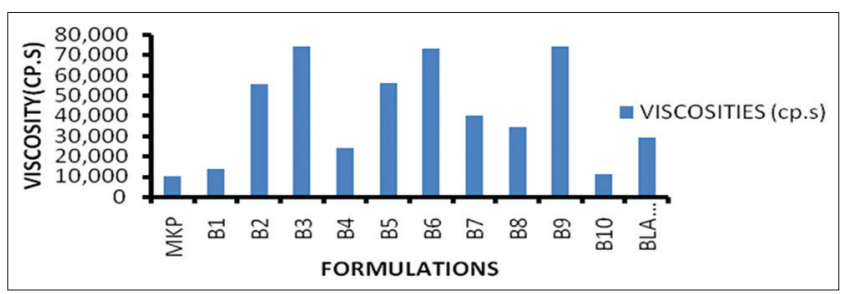

Fig. 7: Viscosity of anti-acne gel of isotretinoin along with marketed product

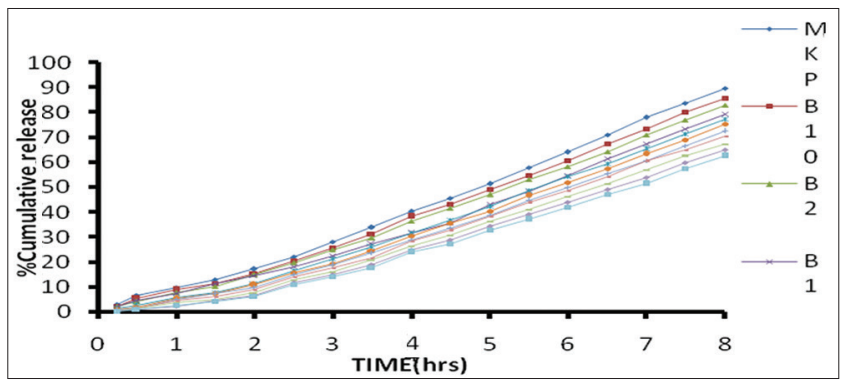

Fig. 8: In vitro release data of the anti-acne gel of isotretinoin $(0.05 \% \mathrm{w} / \mathrm{w})$ and Sortet gel

Physicochemical evaluation of gel formulation

After physicochemical evaluation, it was clear that all the batches have yellow, transparent, homogenous with good homogeneity, smooth in texture. The physical appearance of gel formulations was transparent fresh lemon color between $\mathrm{pH}$ ranges 5.9-6.5.

\section{Spreadability}

The spreadability of the formulations was found in between 4.654 and $32.422 \mathrm{~g} \mathrm{~cm} /$ seconds. Affinity of solvent toward the polymer

Table 6: Interpretation of isotretinoin carried out by IR

\begin{tabular}{lll}
\hline Groups & Ranges & Interpretation \\
\hline OH & 3428.77 & Strong peak of carboxyl group \\
C-H stretch alkene & 2927.53 & Strong peak \\
C==C arbonyl & 1673.04 & Strong peak \\
C==C aliphatic & 1599.32 & Strong peak \\
C=C aromatic & 1564.81 & Strong peak \\
OH deformation & 1447.90 & Broad peak \\
C-C aromatic & 1249.35 & Strong peak \\
C-C aliphatic & 971.49 & Strong peak \\
\hline
\end{tabular}

IR: Infrared

Table 7: IR interpretation of isotretinoin, all excipients mixture

\begin{tabular}{ll}
\hline Peaks $\left(\mathbf{c m}^{-1}\right)$ & Groups \\
\hline 3366.88 -strong & OH \\
1654.79-strong & C=O \\
1249.45 -strong & C-aromatic \\
2971.47 & C-H stretch alkene \\
951.82 & C-C aliphatic \\
\hline IR: Infrared &
\end{tabular}

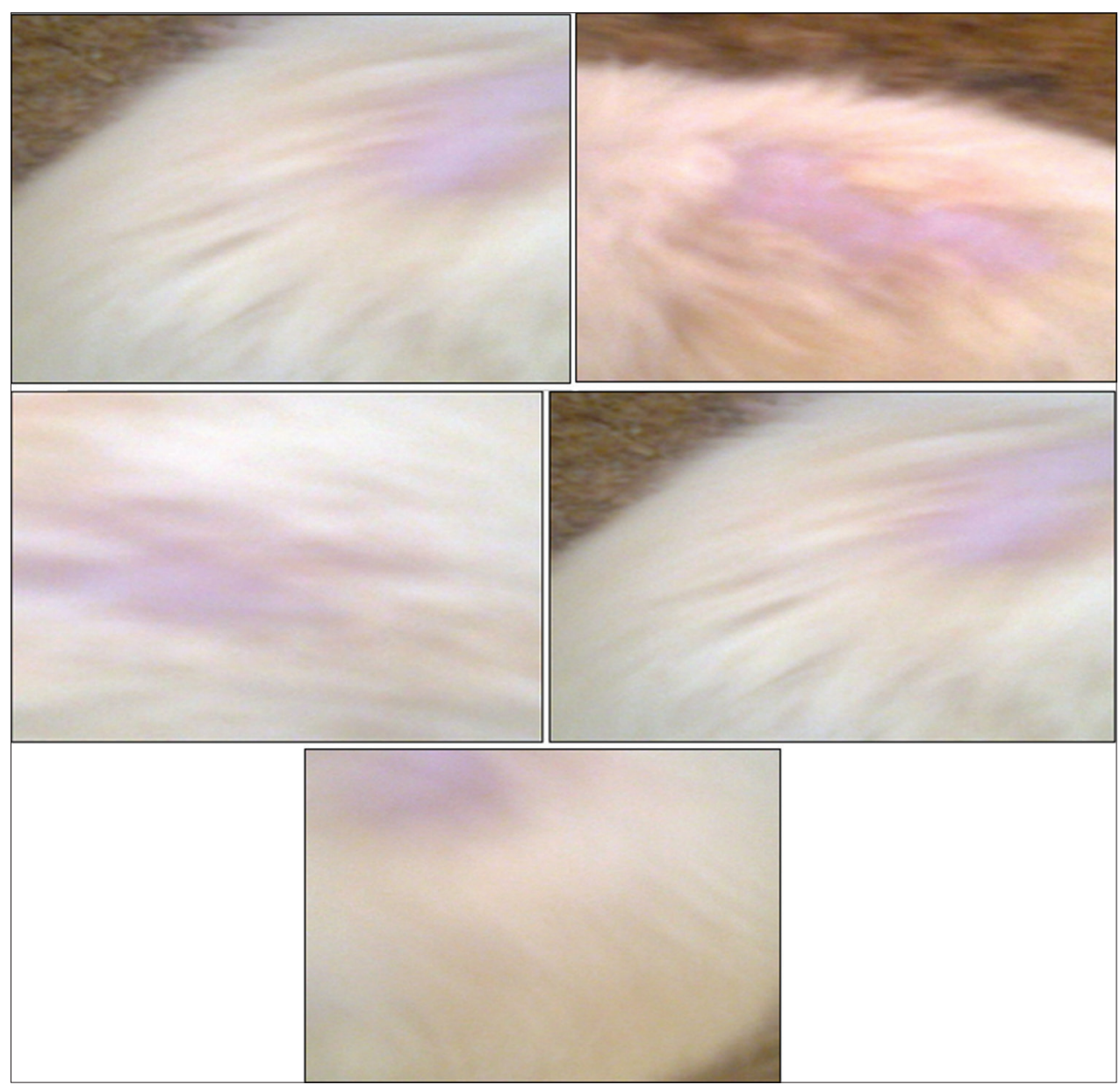

Fig. 9: Photographs of skin irritation study of anti-acne gel of isotretinoin 


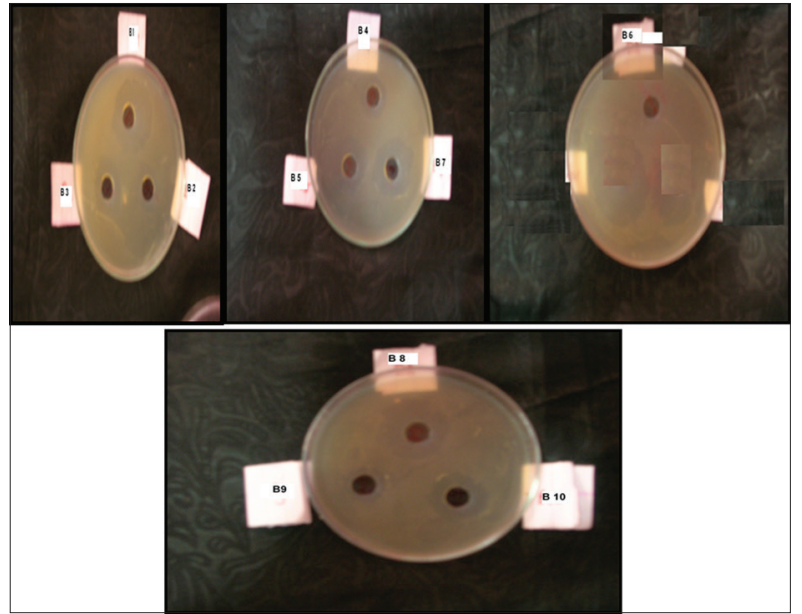

Fig. 10: Photographs of antibacterial study of anti-acne gel of isotretinoin also affects the structure of network of the gel. If solvent have higher affinity toward polymer then polymer chains get extended, that is, increased entanglement, and thus increases swelling of polymer thus, increase viscosity of formulation. And if solvent has low affinity toward solvent, then polymer contracts reduces entanglement. Ethanol has higher affinity toward water than polymer carbopol 940 , that is, it has low affinity toward carbopol 940 , so the gel structure get contracted, so viscosity was less. Hence, Batch B10 have less viscous as compare to other batches, so it has better spreadability $\left(32.6 \mathrm{~g} / \mathrm{cm}^{3}\right)$ and lower than marketed product (Sortet gel $59.116 \mathrm{~g} / \mathrm{cm}^{3}$ ).

\section{Drug content}

The result of drug content was listed in table the drug content of the gel formulations was found to be uniform among various formulations prepared and was found to be in range $89.26-95.60 \%$, from the above result, it was clear that the B10 batch shows maximum drug content, that is, $95.96 \%$. Among all formulations of gel contains mixture of ethanol and isopropyl alcohol, containing more quantity of isopropyl alcohol.

Table 8: Color, physical appearance, homogeneity, feel on application, and pH (mean) of anti-acne gel of isotretinoin

\begin{tabular}{|c|c|c|c|c|c|}
\hline Formulation code & Color & Physical appearance & Homogeneity & Feel on application & pH (mean) \\
\hline MKT PDT & Yellow & Transparent & Homogeneous & Smooth & $6.5 \pm 0.1$ \\
\hline B1 & Yellow & Transparent & Homogeneous & Smooth & $6 \pm 0.1$ \\
\hline B2 & Yellow & Transparent & Homogeneous & Smooth & $6.03 \pm 0.1$ \\
\hline B3 & Yellow & Transparent & Homogeneous & Smooth & $6 \pm 0.1$ \\
\hline B4 & Yellow & Transparent & Homogeneous & Smooth & $6.16 \pm 0.2$ \\
\hline B5 & Yellow & Transparent & Homogeneous & Smooth & $6.06 \pm 0.2$ \\
\hline B6 & Yellow & Transparent & Homogeneous & Smooth & $6 \pm 0.1$ \\
\hline B8 & Yellow & Transparent & Homogeneous & Smooth & $6.06 \pm 0.1$ \\
\hline B9 & Yellow & Transparent & Homogeneous & Smooth & $5.9 \pm 0.1$ \\
\hline B10 & Yellow & Transparent & Homogeneous & Smooth & $6.36 \pm 0.2$ \\
\hline B11 BLANK & & Transparent & Homogeneous & Smooth & $6.23 \pm 0.1$ \\
\hline
\end{tabular}

Table 9: Average spread ability of gel formulations

\begin{tabular}{ll}
\hline Formulation & Average spreadability, $\mathbf{g} / \mathbf{c m}^{\mathbf{3}}$ \\
\hline B1 & 20.367 \\
B2 & 14.603 \\
B3 & 4.654 \\
B4 & 23.005 \\
B5 & 13.668 \\
B6 & 5.851 \\
B7 & 23.508 \\
B8 & 15.123 \\
B9 & 22.784 \\
B10 & 32.422 \\
B11 & 14.998 \\
MKP & 59.116 \\
\hline
\end{tabular}

Table 10: Spreadability of gel formulations

\begin{tabular}{|c|c|c|c|c|c|c|c|c|c|c|c|c|}
\hline Formulations & $1^{\text {st }}$ & $2^{\text {st }}$ & $3^{\text {rd }}$ & $4^{\text {th }}$ & $5^{\text {th }}$ & $6^{\text {th }}$ & $7^{\text {th }}$ & $8^{\text {th }}$ & $9^{\text {th }}$ & $10^{\text {th }}$ & Average spread ability & $\pm \mathrm{SD}$ \\
\hline B1 & 19.7 & 20.37 & 22 & 20 & 19.8 & 19.6 & 20.7 & 20.33 & 17.4 & 23.5 & 20.367 & 1.5 \\
\hline B2 & 14.4 & 14.38 & 14.3 & 15 & 15.1 & 14.8 & 14.4 & 14.38 & 14.4 & 14.7 & 14.603 & 0.3 \\
\hline B2 & 4.66 & 4.68 & 4.66 & 4.7 & 4.65 & 4.51 & 4.67 & 4.68 & 4.69 & 4.65 & 4.654 & 0.05 \\
\hline B3 & 23.1 & 22.85 & 22.6 & 23 & 23.2 & 22.9 & 22.6 & 23.16 & 23.1 & 23.2 & 23.005 & 0.2 \\
\hline B5 & 13.6 & 13.48 & 13.7 & 14 & 14 & 13.8 & 13.7 & 13.62 & 13.5 & 13.5 & 13.668 & 0.1 \\
\hline B6 & 5.87 & 5.59 & 5.96 & 5.9 & 5.87 & 5.86 & 5.88 & 5.85 & 5.85 & 5.87 & 5.851 & 0.09 \\
\hline B7 & 24 & 21.81 & 23.8 & 24 & 23.6 & 23.4 & 23.2 & 23.85 & 23.8 & 23.6 & 23.508 & 0.6 \\
\hline B9 & 22.7 & 22.68 & 22.6 & 23 & 22.7 & 22.6 & 22.4 & 23.03 & 23.1 & 23.2 & 22.784 & 0.2 \\
\hline B10 & 32.6 & 32 & 31.5 & 33 & 32.9 & 32.6 & 32.4 & 32 & 31.7 & 33.3 & 32.422 & 0.6 \\
\hline B11 & 17.8 & 19.04 & 18.3 & 18 & 17.9 & 17.7 & 17.5 & 18.15 & 18 & 17.9 & 17.998 & 0.4 \\
\hline MKP & 59.1 & 57.69 & 59.7 & 59 & 59.4 & 59.7 & 58.5 & 59.11 & 59.7 & 59.4 & 59.116 & 0.6 \\
\hline
\end{tabular}


Table 11: Percent drug content of gel formulations (average \pm SD)

\begin{tabular}{lll}
\hline Formulations & \% Drug contents & ( $\mathbf{)}$ SD \\
\hline B1 & 90.95 & 0.0019 \\
B2 & 93.80 & 0.0031 \\
B3 & 89.26 & 0.0022 \\
B4 & 95.03 & 0.0024 \\
B5 & 91.84 & 0.0036 \\
B6 & 90.53 & 0.0038 \\
B7 & 90.00 & 0.0038 \\
B8 & 90.38 & 0.00113 \\
B9 & 92.00 & 0.0029 \\
B10 & 95.60 & 0.0038 \\
MKP & 99.30 & 0.00114 \\
\hline
\end{tabular}

Table 12: Stickiness evaluation of gel formulations

\begin{tabular}{ll}
\hline Formulations & $\begin{array}{l}\text { Presence or absence of stickiness after } \\
\text { application }\end{array}$ \\
\hline B1 & Absence of stickiness \\
B2 & Absence of stickiness \\
B3 & Absence of stickiness \\
B4 & Absence of stickiness \\
B5 & Absence of stickiness \\
B6 & Absence of stickiness \\
B7 & Absence of stickiness \\
B8 & Absence of stickiness \\
B9 & Absence of stickiness \\
B10 & Absence of stickiness \\
B11 & Absence of stickiness \\
MKP & Absence of stickiness \\
\hline
\end{tabular}

\section{Stickiness}

Evaluation of stickiness was listed in Table 6. From this, it was clear that the formulated gel of isotretinoin was free from stickiness after application, and it was freely get spread on the skin and it was also compared with the marketed formulations.

Smell

The smell of the formulated gel formulations was evaluated by checked it through 4-5 volunteers, and then it was considered as alcoholic, acceptable, and non-acceptable.

\section{Viscosity}

The viscosity of all formulations was evaluated. The viscosity of B10 batch was less as compared to other formulations, ultimately shows more release of B10 Batch. Depending on the concentration of Carbopol 940 and proportion of solvent, the viscosity changes, which affect the release of formulation.

In the process of neutralization of Carbopol 940, neutralization means nothing but ionic repulsion of its charges. The polymer concentration increases repulsion of the chains, and thus increases rigidity of structure of the gel. Affinity of solvent toward the polymer also affects the structure of network of the gel. If solvent have higher affinity toward polymer, then polymer chains get extended, that is, increased. Entanglement and increased swelling of polymer thus increases viscosity of formulation. And if solvent have low affinity toward solvent, then polymer contracts reduces entanglement. Ethanol has higher affinity toward water than polymer Carbopol 940, that is, it has low affinity toward Carbopol 940, so the gel structure gets contracted, so viscosity was less. Hence, batch B10, B1, B4, and B8 had low viscosity as compared to marketed gel of isotretinoin, that is, Sotret gel.

\section{In vitro diffusion study}

The in vitro diffusion study shows combined percentage release patterns of the anti-acne gel of isotretinoin $(0.05 \% \mathrm{w} / \mathrm{w})$. Furthermore, there was a comparison made between the marketed formulations of the same drug, that is, isotretinoin Sortet gel $0.05 \% \mathrm{w} / \mathrm{w}$. It is observed from the
Table 13: Evaluation of smell of gel formulations

\begin{tabular}{llll}
\hline Formulations & \multicolumn{2}{l}{ Smell } & \\
\cline { 2 - 4 } & Alcoholic & Acceptable & Non-acceptable \\
\hline B1 & ++ & + & - \\
B2 & ++ & + & - \\
B3 & - & + & - \\
B4 & ++ & + & - \\
B5 & ++ & + & - \\
B6 & ++ & + & - \\
B7 & ++ & + & - \\
B8 & ++ & + & - \\
B9 & ++ & + & - \\
B10 & + & + & - \\
B11 & + & + & - \\
MKP & - & + & - \\
\hline
\end{tabular}

Symbolised; ++ alcoholic, + Acceptable, -- Non-acceptable

Table 14: Viscosities of gel formulations

\begin{tabular}{ll}
\hline Formulations & Viscosity (CP.S) \\
\hline MKP & 10,300 \\
B1 & 14000 \\
B2 & 55,500 \\
B3 & 74,500 \\
B4 & 24230 \\
B5 & 56200 \\
B6 & 73300 \\
B7 & 40000 \\
B8 & 34400 \\
B9 & 74100 \\
B10 & 11502 \\
BLANK, B11 & 29400 \\
\hline
\end{tabular}

result that batch B10 showed more diffusion, that is, release from all the formulations, that is, $85.69 \%$ after the Sortet gel, because of decrease in viscosity. The marketed product showed $89.72 \%$ release and the batch B3 showed low release, that is, $62.43 \%$, because of higher viscosity

\section{Acute skin irritation study}

The formulations were non-irritant and did not show any skin toxicity when applied daily for 7 days in albino rats. The skin irritation studies show that anti-acne gel formulations dose not produces any severe irritation, redness of skin, along with the marketed Sotret gel of isotretinoin while the $0.8 \%$ formalin was used as a standard irritant for the comparison. Thus, all formulation does not produce any skin irritation and safe to use.

\section{Antibacterial study}

The zones of inhibitions for the antibacterial activity were compared with the standard benzoyl peroxide gel, marketed preparation of isotretinoin, that is, Sotret gel for acne vulgaris. Formulation B1 has shown comparable zones of inhibitions to that of the marketed preparation. All the formulations have shown greater zones of inhibitions. Zones of inhibitions for benzoyl peroxide were found to be greater than that of all the formulations (B1-B10) as well as marketed preparation. While the zones of inhibitions for all the formulations are $>10.4 \mathrm{~mm}$. This suggests that the other active ingredients of the formulations containing solvents such as ethanol and isopropyl alcohol may have contributory antibacterial activity. Their activity is probably due to their ability to complex with extracellular and soluble proteins and to complex with bacterial cell walls. P. acnes, an anaerobic pathogen, is implicated in the development of inflammatory acne. The formulations having antibacterial agents inhibiting the P. acnes, may also reduce the development of inflammatory acne.

\section{CONCLUSION}

1. This study has analyzed the formulation of anti-acne gel of isotretinoin and it was found to have significant activity against $P$. acne. 
Table 15: Cumulative percentage release of the anti-acne gel of isotretinoin and marketed Sortet gel

\begin{tabular}{|c|c|c|c|c|c|c|c|c|c|c|c|}
\hline \multirow{2}{*}{$\begin{array}{l}\text { Time } \\
\text { (hrs) }\end{array}$} & \multicolumn{11}{|c|}{ Cumulative percentage release of the anti-acne gel of isotretinoin and marketed Sortet gel } \\
\hline & MKP & B10 & B1 & B4 & B8 & B7 & B2 & B5 & B6 & B9 & B3 \\
\hline 0.25 & 3.070018 & 2.359529 & 2.162902 & 2.09736 & 1.376392 & 1.179765 & 0.983137 & 0.78651 & 0.589882 & 0.52 & 0.39 \\
\hline 1 & 9.773961 & 8.752523 & 7.83566 & 7.297882 & 5.686522 & 5.22868 & 5.111033 & 4.521333 & 3.695608 & 2.345653 & 2.555425 \\
\hline 1.5 & 12.94175 & 11.39634 & 10.28322 & 11.38437 & 7.925882 & 7.467634 & 7.218902 & 6.196915 & 5.017699 & 4.685673 & 4.061621 \\
\hline 2 & 17.14423 & 15.25859 & 14.91927 & 14.40745 & 11.4617 & 10.75454 & 9.627608 & 9.025569 & 7.715817 & 6.662823 & 6.170222 \\
\hline 2.5 & 22.26303 & 20.60089 & 19.84199 & 18.26878 & 16.56926 & 15.77059 & 14.97192 & 13.98988 & 12.89038 & 11.62805 & 10.92593 \\
\hline 3 & 27.93085 & 25.7972 & 24.72384 & 22.56167 & 21.37341 & 19.36902 & 18.74102 & 17.57579 & 16.17508 & 15.01806 & 1475 \\
\hline 3.5 & 33.81998 & 31.28055 & 29.7749 & 27.03702 & 25.87472 & 24.40865 & 23.60942 & 21.85561 & 21.03208 & 18.85289 & 17.77132 \\
\hline 4 & 40.19276 & 38.19148 & 36.31927 & 31.45898 & 31.55488 & 30.33828 & 28.88473 & 28.41524 & 26.54304 & 24.73169 & 23.91265 \\
\hline 4.5 & 45.60726 & 43.25232 & 41.49867 & 35.68358 & 36.81417 & 35.53221 & 33.56795 & 32.65255 & 30.83336 & 28.79961 & 27.40395 \\
\hline 5 & 51.34894 & 48.98128 & 46.95276 & 43.22416 & 42.45273 & 40.38445 & 38.82724 & 38.47558 & 36.56507 & 34.29584 & 32.80886 \\
\hline 5.5 & 57.77163 & 54.69645 & 53.08787 & 48.48162 & 48.7458 & 46.53391 & 44.53135 & 43.74685 & 41.29929 & 39.04369 & 37.01966 \\
\hline 6 & 64.04925 & 60.67323 & 58.22586 & 54.64306 & 54.18573 & 51.97438 & 49.78881 & 48.79461 & 46.387 & 43.85652 & 41.93799 \\
\hline 6.5 & 70.87681 & 67.25242 & 64.20264 & 61.45901 & 59.57281 & 57.40123 & 55.36036 & 54.37942 & 51.53971 & 49.10146 & 47.02607 \\
\hline 7 & 77.92641 & 73.26659 & 71.10865 & 67.48735 & 65.2611 & 63.23404 & 60.81336 & 60.44863 & 56.99344 & 54.04429 & 51.28768 \\
\hline 8 & 89.72165 & 85.69221 & 82.97087 & 79.20544 & 77.26732 & 75.20105 & 72.37459 & 70.63346 & 67.46769 & 65.00421 & 62.43208 \\
\hline
\end{tabular}

Table 16: Acute skin irritation test observation

\begin{tabular}{|c|c|c|c|c|c|c|c|}
\hline Treatment & Day 1 & Day 2 & Day 3 & Day 4 & Day 5 & Day 6 & Day 7 \\
\hline Control & $\mathrm{A}$ & $\mathrm{A}$ & $\mathrm{A}$ & $\mathrm{A}$ & $\mathrm{A}$ & $\mathrm{A}$ & $\mathrm{A}$ \\
\hline Standard ( $0.8 \%$ formalin solution) & $\mathrm{B}$ & $\mathrm{B}$ & $\mathrm{B}$ & $\mathrm{B}$ & $\mathrm{B}$ & $\mathrm{B}$ & $\mathrm{B}$ \\
\hline B1 $(0.5 \%)$ & $\mathrm{A}$ & $\mathrm{A}$ & $\mathrm{A}$ & $\mathrm{A}$ & $\mathrm{A}$ & $\mathrm{A}$ & $\mathrm{A}$ \\
\hline B2 & $\mathrm{A}$ & $\mathrm{A}$ & $\mathrm{A}$ & $\mathrm{A}$ & $\mathrm{A}$ & $\mathrm{A}$ & $\mathrm{A}$ \\
\hline B3 & $\mathrm{A}$ & $\mathrm{A}$ & $\mathrm{A}$ & $\mathrm{A}$ & $\mathrm{A}$ & $\mathrm{A}$ & $\mathrm{A}$ \\
\hline B4 & $\mathrm{A}$ & A & A & $\mathrm{A}$ & $\mathrm{A}$ & A & A \\
\hline B5 & A & A & A & A & A & A & A \\
\hline B7 & $\mathrm{A}$ & A & A & A & A & $\mathrm{A}$ & A \\
\hline B8 & A & A & A & A & A & A & A \\
\hline B9 & $\mathrm{A}$ & A & A & A & A & $\mathrm{A}$ & A \\
\hline B10 & A & A & A & A & A & A & A \\
\hline MKP & $\mathrm{A}$ & A & A & A & A & $\mathrm{A}$ & A \\
\hline
\end{tabular}

Table 17: Zone of inhibition of gel formulation

\begin{tabular}{|c|c|c|c|c|}
\hline \multirow[t]{2}{*}{ Formulations } & \multicolumn{3}{|c|}{ Zone of inhibition in $\mathrm{mm}$} & \multirow[t]{2}{*}{ Mean \pm SD } \\
\hline & 1 & 2 & 3 & \\
\hline B1 & 30.4 & 30.8 & 30.5 & $30.566 \pm 0.20$ \\
\hline B2 & 20.6 & 21.2 & 21.6 & $21.13333 \pm 0.503322$ \\
\hline B3 & 24.3 & 24.6 & 23.9 & $24.26667 \pm 0.351188$ \\
\hline B4 & 22.1 & 22.6 & 21.8 & $22.16667 \pm 0.404145$ \\
\hline B5 & 25.8 & 26.4 & 26.3 & $26.16667 \pm 0.321455$ \\
\hline B7 & 28.4 & 27.8 & 28.6 & $28.26667 \pm 0.416333$ \\
\hline B8 & 30.5 & 30.8 & 30.2 & $30.5 \pm 0.3$ \\
\hline B9 & 18.4 & 17.9 & 18.8 & $18.36667 \pm 0.450925$ \\
\hline $\mathrm{B} 10$ & 24.2 & 24.6 & 23.9 & $24.23333 \pm 0.351188$ \\
\hline Benzyl Peroxide gel (+ control) & 40.2 & 40.2 & 40.5 & $40.3 \pm 0.173205$ \\
\hline Marketed SOTRET gel & 35.5 & 35.8 & 35.3 & $35.53333 \pm 0.251661$ \\
\hline Distill water (- control) & - & - & - & - \\
\hline
\end{tabular}

2. The gel formulation was subjected to physicochemical analysis, spreadability, viscosity, drug content, in vitro diffusion study, skin irritation study, and antibacterial study.

3. Further studies are needed to identify exact effect of isotretinoin as anti-acne effect.

4. The study has laid the foundation for discovering an effective topical gel formulation of isotretinoin with possibly lower side effects to treat human nodulosystic acne vulgaris.

\section{ACKNOWLEDGMENT}

The author wish to acknowledge the technical support provided by Rajarambapu college of Pharmacy, Kasegaon, for carrying out evaluations as well as animal study.

\section{REFERENCES}

1. Atar M, Kausar A, Reheman A. Preparation of new formulation of anti-acne creams and their efficacy. Afr J Pharm Pharmacol 
2010;4(6):298-303.

2. Ofner CM, Cathy M, Gells and Jellies. Encyclopaedia of Pharmaceutical Technology. $3^{\text {rd }}$ ed. Philadelphia, PA: University of the Sciences; 2007. p. 1875.

3. Rowe RC, Owen SC. Handbook of Pharmaceutical Excipients. $5^{\text {th }}$ ed. London: PHP Pharmaceutical Press; 2006. p. 111-4.

4. Waghmare N, Waghmare S, Wani S, Yerawar A. Development of isotretinoin gel for the treatment of acne vulgaris. Res J Pharm Biol Chem Sci 2011;2(1):220-30

5. Vijayalakshmi A, Tripura A, Ravichandiran V. Development and evaluation of anti-acne products from Terminalia Arjuna bark. Int J Chem Technol Res 2011;3(1):320-7.
6. British Pharmacopoeia Commission. British Pharmacopoeia. Vol. 1-2. London: H.M. Stationary Office; 2009. p. 2431.

7. Linebenberg W, Engelbrecht E. A comparative study of the release of active ingredients from semisolid cosmeceuticals measured with Franz enhancer or flow through cell diffusion apparatus. J Food Drug Anal 2004;12(1):19-28.

8. Sawarkar H, Khadabadi S, Mankar D, Farooqui I, Jagtap N. Development and biological evaluation of herbal anti-acne gel. Int $\mathrm{J}$ Pharmtech Res 2010;2(3):2028-31

9. Jain S, Diwan A. Use of lactic acid and span 80 in the formulation of lipid based imiquimod vesicles for genital warts. Int J Pharm Pharm Sci 2017;9(2):292-301. 